\title{
Response
}

\author{
Huoyan Liang, Xianfei Ding and Tongwen Sun ${ }^{*}$ (D) \\ This comment refers to the article available at https://doi.org/10.1186/s13054-019-2392-y
}

To the Editor:

We thank Dr. Ye and colleagues [1] for their interest in our article in Critical Care [2]. First, we agree with their view that diabetes covariates may affect the efficacy of preadmission metformin use in septic patients with diabetes. Although one retrospective large database review [3] reported that diabetes was not associated with adjusted 90-day mortality risk in critically ill patients admitted with sepsis, our study used adjusted ORs and 95\% CIs, which were corrected for the diabetes covariate or which balanced the blood glucose variation between the metformin and non-metformin groups. When the unadjusted ORs and 95\% CI data were extracted in one study [4], they showed negative results between metformin and non-metformin use. Therefore, neither the covariates of diabetes nor variations in blood glucose levels had significant effects on the outcomes of our study. Second, we acknowledge that we did not adequately discuss heterogeneity in our study, although all meta-analyses have varying degrees of heterogeneity. Therefore, the Simplified Acute Physiology Score II, Acute Physiology and Chronic Health Evaluation II (APACHE) II score, and the Sequential Organ Failure Assessment (SOFA) score baselines may not have been the factors that lead to the heterogeneity in our study. Third, we thank Dr. Ye and colleagues for pointing out our mistake in the number of included studies in the discussion section of our study. Finally, we believe that clinical trials will confirm the relationship between diabetes and mortality in patients with sepsis, and the studies to assess the association between metformin and mortality in septic patients with diabetes will be performed.

\author{
Availability of data and materials \\ Not applicable.

\begin{abstract}
Authors' contributions
LHY and DXF designed the study. STW edited the English text of this manuscript. All authors participated in drafting and reviewing the manuscript. All authors read and approved the final version of the manuscript.
\end{abstract}

Ethics approval and consent to participate

Not applicable.

Consent for publication

Not applicable.

Competing interests

The authors declare that they have no competing interests.

\section{Publisher's Note}

Springer Nature remains neutral with regard to jurisdictional claims in published maps and institutional affiliations.

Received: 29 March 2019 Accepted: 26 April 2019

Published online: 20 May 2019

\section{References}

1. Ye J, Liang $\mathrm{Q}, \mathrm{Xi}$ X. Some questions about preadmission metformin use and mortality in patients with sepsis and diabetes mellitus. Critical care (London, England). 2019;23(1):96.

2. Liang H, Ding X, Li L, Wang T, Kan Q, Wang L, Sun T. Association of preadmission metformin use and mortality in patients with sepsis and diabetes mellitus: a systematic review and meta-analysis of cohort studies. Critical care (London, England). 2019;23(1):50.

3. van Vught LA, Holman R, de Jonge E, de Keizer NF, van der Poll T. Diabetes is not associated with increased 90 -day mortality risk in critically ill patients with sepsis. Crit Care Med. 2017;45(10):e1026-35.

4. van Vught $L A$, Scicluna BP, Hoogendijk AJ, Wiewel MA, Klein Klouwenberg PM, Cremer OL, Horn J, Nurnberg P, Bonten MM, Schultz MJ, et al. Association of diabetes and diabetes treatment with the host response in critically ill sepsis patients. Critical Care (London, England). 2016;20(1):252.

\section{Acknowledgements}

None.

Funding

None.

\footnotetext{
* Correspondence: suntongwen@163.com

General ICU, The First Affiliated Hospital of Zhengzhou University, Henan Key Laboratory of Critical Care Medicine, Zhengzhou 450052, China
}

(c) The Author(s). 2019 Open Access This article is distributed under the terms of the Creative Commons Attribution 4.0 International License (http://creativecommons.org/licenses/by/4.0/), which permits unrestricted use, distribution, and reproduction in any medium, provided you give appropriate credit to the original author(s) and the source, provide a link to the Creative Commons license, and indicate if changes were made. The Creative Commons Public Domain Dedication waiver (http://creativecommons.org/publicdomain/zero/1.0/) applies to the data made available in this article, unless otherwise stated. 